\title{
A questão do espaço nas correspondências entre Leibniz e Clarke
}

\section{The concept of space in the Leibniz- Clarke correspondence}

\author{
Patricia Coradim Sita \\ Professora da Universidade Estadual de Maringá
}

Resumo: Neste trabalho procuramos descrever alguns pontos importantes para o entendimento de aspectos básicos da teoria leibniziana do espaço, mais especificamente, pontos referentes à sua crítica ao modelo de espaço newtoniano que envolve (1) a idéia de que o espaço é o órgão de que Deus se serve para sentir as coisas, (2) a idéia da anterioridade do espaço e do tempo em relação às coisas e (3) a interferência necessária de Deus no mundo, ou a insuficiência de meios naturais para explicar o mundo. Esses assuntos são amplamente explorados nas famosas correspondências com Clarke, correspondências que constituem importante fonte de pesquisa das ideias de Leibniz e dos newtonianos sobre a matéria, o movimento, o tempo e o espaço, e base para nossas análises. Nosso objetivo é contribuir para o entendimento das concepções básicas sobre o espaço a partir da investigação dos pontos apontados para permitir compreender mais precisamente o que está em questão quando se propõe o modelo absoluto ou relativo de espaço.

Palavras-chave: filosofia natural, vazio, metafísica, espaço absoluto, espaço relativo. 
The thought of Leibniz is notoriously complex and comprehensive dialogue with a number of research areas, scientific and philosophical. In this paper we describe some important points for the basic aspects of the theory Leibnizian space, more specifically, to its critical points related to the Newtonian space model that involves (1) the idea that space is the body that God serves to sense things, (2) the idea of anteriority of space and time in relation to things, and (3) the necessary interference of God in the world, or the lack of natural means to explain the world. These issues are widely exploited in the famous correspondence with Clarke, matches that are important source of research ideas of Leibniz and the Newtonians over matter, motion, time and space, and as a basis for our analysis. Our goal is to contribute to the understanding of the concepts of space from the investigation of the points mentioned.

Keywords: natural philosophy; metaphysics; relative space; absolute space.

As correspondências entre Leibniz e Clarke foram iniciadas em 1715 com uma pequena carta (cerca de 4 parágrafos) de Leibniz para Wilhelmine Caroline, Princesa de Gales. Há nesta carta, entre outros, um comentário crítico sobre a tese newtoniana de que o espaço pode ser considerado a sede da percepção divina. A princesa se encarregou de encaminhá-la para Samuel Clarke, um influente teólogo inglês do século XVIII, newtoniano, provocando o início das correspondências que constituem importante fonte de pesquisa sobre a natureza do espaço e do tempo vistos em si mesmos e sob o pano de fundo da metafísica ${ }^{1}$.

Até a morte de Leibniz, que encerra a correspondência um ano depois do seu início, foram percorridas múltiplas áreas do saber, o que inclui questões relativas à teologia, física, metafísica, moral. A ampla abordagem temática fez a correspondência crescer sensivelmente em tamanho: a última carta de Leibniz contém 130 parágrafos distribuídos em mais de 40 páginas

1 Devemos salientar que as concepções leibnizinas de espaço e tempo em articulação com as unidades substanciais aparecem anteriormente, em uma formulação muito bem elaborada, nas correspondências trocadas entre 1698 e 1706 com De Volder (GP, II). Neste texto, entretanto, nosso objetivo é analisar essas concepções à luz das correspondências com Clarke. 
nas quais o autor repercute e reage a cada um dos comentários anteriores de Clarke.

No centro do debate estava o modo como os autores concebiam o espaço e a realidade física e sua adequação a uma proposta metafísica subjacente. As objeções de Leibniz à concepção newtoniana, inclusive a que inicia as correspondências, podem ser reduzidas aos mesmos pontos centrais, de cujos desdobramentos se ocupam as cartas. Primeiramente está a ideia de que o espaço é o Sensorium Dei, tese que envolve a premissa da anterioridade do tempo e do espaço em relação às coisas, e em segundo lugar está a tese de que Deus, de vez em quando, 'precisa dar corda no seu relógio' porque senão ele deixaria de funcionar, o que supõe a necessidade de um eventual ajuste não mecânico na natureza para que ela continue a ser operada pelas mesmas leis que a mantém. Esses pontos contemplam requisitos importantes da teoria newtoniana que são rechaçados por Leibniz e que serão objeto da nossa análise.

Leibniz critica, em sua primeira carta para a Princesa de Gales, o que ele considera ser uma afirmação ímpia de Newton: que "o espaço é o órgão de que Deus se serve para sentir as coisas" (Leibniz, 1979, correspondência I, art. 3). Leibniz parece estar se referindo diretamente ao texto newtoniano da Óptica, publicado em 1704, no qual se pode ler:

Is not the Sensory of Animals that place to which the sensitive Substance is present, and into which the sensible Species of Things are carried through the Nerves and Brain, that there they may be perceived by their immediate presence to that Substance? And these things being rightly dispatch'd, does it not appear from Phaenomena that there is a Being incorporeal, living, intelligent, omnipresent, who in infinite Space, as it were in his Sensory, sees the things themselves intimately, and throughly perceives them, and comprehends them wholly by their immediate presence to himself: Of which things the Images only carried through the Organs of Sense into our little Sensoriums, are there seen and beheld by that which in us perceives and thinks. (NEWTON, 1952, p.370, q.28, grifo nosso) 
Para Leibniz não restam dúvidas de que isso significa um compromisso de Newton com certa ideia sobre a percepção que Deus tem do mundo e sobre a própria relação entre Deus e o mundo que, para Leibniz, é inaceitável.

Do ponto de vista da razão o elemento central da crítica de Leibniz se apresenta frágil e muito geral. Ao longo de toda a correspondência o filósofo procura manter-se centrado na defesa de uma concepção de espaço relacional fixada sobre a hipótese necessária da aceitação do Princípio de Razão Suficiente (PRS). Desse modo, cabe sempre a Leibniz apresentar as críticas e argumentos, dirigindo a discussão, enquanto Clarke reage ao proposto e se limita a responder. Isso pode ser notado no próprio formato das correspondências: as cartas de Leibniz apresentam as novas abordagens, desdobram-se em parágrafos e argumentos, e as cartas de Clarke são uma retomada quase literal, em algumas passagens, das questões levantadas por Leibniz, mantendo-se dentro dos limites propostos pelo interlocutor.

Leibniz oferece para a afirmação de Newton sobre o espaço duas possibilidades de interpretação igualmente condenáveis: como (1) contendo uma identificação entre Deus e o espaço ou como (2) afirmando que o espaço é incriado e, portanto, independente de Deus. Ambas são consideradas problemáticas e inaceitáveis. Leibniz alega que tais considerações são, na melhor das hipóteses, profundamente enganosas, e, na pior das hipóteses, heréticas.

Sobre a primeira tese ele afirma:

Tenho ainda outras razões contra a estranha imaginação de que o espaço é uma propriedade de Deus. Neste caso, o espaço entra na essência de Deus. Ora, o espaço tem partes; logo, haveria partes na essência de Deus, afirmação inconcebível. Além disso, os espaços ora são vazios, ora cheios, e portanto haveria na essência de Deus partes ora vazias, ora cheias, sujeitas consequentemente a uma mudança perpétua. (LEIBNIZ V, art. 42, p. 200)

A segunda tese também é inadmissível. Para Leibniz não é possível falar em um espaço existente "fora" do universo, ou além dele, onde não há corpos. Da afirmação newtoniana cita- 
da acima Leibniz retira uma conclusão que está presente em todas as suas críticas dirigidas a Newton e que também pode ser dividida em duas partes. (1) o estabelecimento de Deus como dependente de algo: a auto-suficiência divina é questionada quando se afirma a necessidade do espaço para que ele sinta as coisas; (2) o estabelecimento do espaço como independente de Deus e das coisas por ele criadas, resultando em um espaço que é, em si mesmo.

É possível analisar sua primeira crítica à concepção newtoniana sobre o mundo do ponto de vista metafísico, envolvendo uma disputa acerca da liberdade e da manifestação do poder de Deus; mas também é possível analisar sua crítica do ponto de vista da física ordenadora do mundo, que implica em discordâncias em relação à plenitude do espaço. Para Leibniz (1979, p. 183) o espaço é desprovido de substancialidade: ele é uma relação exterior de substâncias. Isso significa que o espaço não pode ser pensado em si mesmo como algo independente das coisas. Ao contrário, o espaço só existe em função das coisas.

Afirmar o espaço independente é aceitar a anterioridade do espaço em relação ao mundo criado, o que implica afirmar que as coisas estão alocadas em um espaço que, sendo infinito, admite vazios - como equivalentes à ausência de qualquer criação em uma determinada coordenada espacial. Da concepção de espaço absoluto Newton deriva suas teses sobre o espaço relativo, movimentos absoluto e relativo, lugar e tempo.

Newton parece reconhecer que 'espaço absoluto’ é a designação de um conceito cujo foco não é o que se pode chamar de realidade do mundo material ${ }^{2}$, mas apenas uma designação aplicável à geometria, permitindo o desenvolvimento de teses sobre relações em um espaço puramente matemático. $\mathrm{O}$ espaço absoluto pode ser entendido apenas como entidade ontológica e base de referência ao movimento dos corpos.

Para Leibniz a discussão da natureza do espaço não pode se dar a despeito do modo como ele é ocupado, e é derivada da discussão sobre os princípios. Essa é outra perspectiva

$2 \quad$ "O espaço absoluto, por sua natureza, sem nenhuma relação com algo externo, permanece sempre semelhante e imóvel”. (NEWTON, 1990, Escólio). 
que ele assume nas suas críticas às concepções newtonianas. Se não há definição dos princípios fundadores do universo, não há definição possível e definitiva do espaço ou do tempo, nem qualquer possibilidade de obtenção de conhecimento verdadeiro. Na ausência deles, dos princípios, a realidade seria fruto do acaso. Dado o acaso, contraposto da ordem como elemento primordial e inaugural do universo físico, o único tipo de conhecimento possível seria o relativo ${ }^{3}$, de modo que nada se poderia afirmar definitivamente.

A disposição do filósofo como proponente de uma teoria do conhecimento, exigente de princípios bem definidos e de um sólido ponto de partida, além das suas especulações acerca de temas metafísicos e da filosofia da natureza, se faz notar aqui. Os princípios defendidos por Leibniz podem ser originários ou derivados. Sem os primeiros não se pode afirmar os segundos. Dentre os primeiros, o PRS é o mais discutido nas correspondências, seguido pelo princípio de identidade dos indiscerníveis (PII). Para Leibniz (1979, p. 182) uma simples vontade sem razão é uma ficção contrária não somente à perfeição de Deus, mas ainda quimérica, contraditória e incompatível com a definição da vontade.

É exigido, pelo PRS, que haja alguma razão para ter-se criado o mundo tal como foi feito. A defesa de um espaço absoluto viola esse princípio, pois, suposta a criação do mundo em um espaço homogêneo absoluto, não haveria razão para seu estabelecimento em um ponto específico desse espaço em detrimento de outro.

Ainda contra a tese do espaço absoluto Leibniz se utiliza do PII. Através dele é sugerido que quando não podemos identificar uma diferença reconhecível entre duas coisas ou entre suas possibilidades elas são, na verdade, apenas uma:

\footnotetext{
$3 \quad$ O mundo, fruto de um acaso que não está apenas no início, mas que perdura no tempo, não contempla qualquer ordenamento e, nesse caso, impossibilita o conhecimento verdadeiro ao modo cartesiano da clareza e distinção, ficando todo conhecimento restrito às pequenas inferências relativas a eventos particulares.
} 
Pôr duas coisas indiscerníveis é admitir a mesma coisa sob dois nomes. Assim, a hipótese de que o universo poderia ter tido primeiro uma outra posição temporal e local do que a que aconteceu efetivamente, e que entretanto todas as suas partes teriam a mesma posição relativa que a recebida com efeito, é uma ficção impossível. (LEIBNIZ IV, art. 6, p. 183)

Sendo o espaço absoluto, o mundo, em relação ao espaço, poderia ocupar qualquer outra posição de modo que nem mesmo a Deus o reconhecimento de qualquer diferença entre este suposto mundo e o mundo atual seria possível. Logo, se a afirmação de um suposto espaço absoluto conduz a uma violação do PII, para Leibniz essa suposição deveria ser abandonada.

Ambos os princípios mencionados são apresentados como parte de um argumento que parece ao filósofo ser definitivo contra a postulação de um espaço absoluto. Recordamos esses princípios norteadores da substância simples para salientar qual a natureza do universo leibniziano que suporta sua concepção de espaço relacional.

Dado um espaço absoluto, incriado, ele seria condição prévia da possibilidade das coisas. Num universo como esse as substâncias dependeriam da pré-existência do espaço, já que, para Leibniz, sendo anterior ao que foi criado, ele receberia as substâncias. Ora, isso significaria o rompimento da autonomia das substâncias. A fundamentação metafísica do sistema leibniziano exige a negação do espaço absoluto, visto que este pressupõe a dependência ontológica das suas substâncias componentes, o que quer dizer que essas substâncias exigiriam, suposto o espaço absoluto, algo que lhes fosse exterior como condição de sua própria possibilidade. $\mathrm{O}$ espaço, sendo absoluto e independente das coisas que o ocupam, seria como uma substância, visto que apenas as substâncias são por si mesmas. Tal é o que se dá no espaço newtoniano que, livre de qualquer compromisso metafísico, dispensa em seu sistema a autonomia ontológica e a não-substancialidade das coisas, e afirma o espaço absoluto.

Ao afirmar a relatividade do espaço, Leibniz estrutura uma física em que os corpos lhes são anteriores. As substâncias individuais criadas são independentes e anteriores à criação do 
espaço que foi concebido justamente para acomodar as substâncias combinadas e agregadas em corpos.

Para Leibniz o princípio de tudo o que há é a substância. Uma vez designada como passível de se tornar existente no mundo criado ela atrai para si as matérias primeira e segunda que, juntas em torno de certa substância dominante, dão origem aos corpos. Deus pode decidir acerca da existência dos possíveis, mas não pode definir ou alterar sua essência. Magnitude, figura e movimento são qualidades dos corpos assim como a percepção e a apetição são qualidades da alma. Se a uma determinada substância será dado o direito à existência é uma opção que cabe a Deus analisar, com base em critérios assegurados pelo PRS e pelo Princípio do Melhor. Entretanto, as determinações internas dessa substância independem da vontade divina. Essa foi a forma encontrada pelo filósofo para assegurar a liberdade individual. É um requisito das substâncias que elas sejam capazes de autodeterminação e livres de qualquer interferência externa, seja de outras substâncias, seja de Deus.

A questão básica a que voltamos é que, se por um lado a metafísica de Leibniz defende a existência de substâncias simples, por outro a sua física parece pressupor um espaço anterior a essas substâncias, já que, para que elas existam, é preciso que existam num lugar e não em outro ${ }^{4}$. É, entretanto, justamente a defesa de um espaço anterior ao mundo criado que compõe uma das críticas de Leibniz aos newtonianos. Ele busca uma alternativa para que não precise aceitar uma noção de espaço

$4 \quad$ Para Leibniz a idéia de lugar corresponde a de espaço. "Lugar é aquilo que se diz ser o mesmo em relação a $A$ e a $B$, quando a relação de coexistência de $B$ com $C, E, F, G$, etc, convém inteiramente com a relação de coexistência que A tivera com os mesmos, supondo-se que não tenha havido nenhuma causa de mudança em C, E, F, G, etc. Poder-se-ia dizer também, sem "ectese" que lugar é aquilo que é o mesmo em momentos diferentes de dois existentes, embora diferentes, quando suas relações de coexistência com certos existentes, que desde um desses momentos até outro são supostos fixos, convêm inteiramente (...). Enfim, espaço é o que resulta dos lugares tomados conjuntamente." (Leibniz V, art. 47, p.201). Já Newton considera o lugar, que pode ser relativo ou absoluto, como sendo a parte do espaço ocupada por um corpo. Desse modo o corpo está sempre em um lugar que, por sua vez, está nos corpos. (Newton, 1990, Escólio, III). A idéia newtoniana de lugar também envolve a discussão sobre a natureza do movimento, como em Leibniz. 
cuja natureza é concorrente com a divina: essa alternativa se traduz pela afirmação de que o espaço, sem os corpos, "não é senão a possibilidade de aí os pôr" (Leibniz III, art. 5). Logo, a saída não deve ser buscada em um espaço real em si mesmo, mas no espaço como relação entre os corpos e, deste modo, como posterior aos corpos.

Ainda que essa saída pareça satisfatória do ponto de vista da sua anterioridade em relação a Deus, resta ao filósofo qualificar o espaço. Sua caracterização deve deixar de ser meramente negativa (não é uma substância, não é absoluto): o espaço é uniforme e, portanto, não tem partes distintas que possam ser destacadas umas das outras, ou seja, que possam ser escolhidas em detrimento de outras (Leibniz III, art.3).

Desse modo, o espaço defendido pela filosofia natural leibniziana é pleno e relacional (ou emergente), definido, como vimos, como a "ordem da coexistência dos corpos":

A meu ver, o espaço é algo puramente relativo, como o tempo; a saber, na ordem das coexistências, como o tempo na ordem das sucessões. De fato, o espaço assinala em termos de possibilidade uma ordem das coisas que existem ao mesmo tempo, enquanto existem junto, sem entrar em seu modo de existir. E quando se vêem muitas coisas junto, percebe-se essa ordem das coisas entre si. (LEIBNIZ III, art. 4, p. 177).

Isso significa afirmar que o espaço é dependente da existência de corpos e ordenador da relação entre eles, a chamada co-existência. Não havendo corpos, não haveria espaço. Neste panorama um suposto espaço desprovido de corpos, um espaço vazio, seria uma concepção destituída de qualquer sentido. Pela definição citada acima a relação entre os corpos, determinante do espaço, parece orientada não por necessidades quantitativas, mas por necessidades qualitativas.

A realidade leibniziana é uma soma de substâncias pontuais existentes em si mesmas que, ao serem combinadas, engendram o fenômeno da extensão. A extensão, que não é, portanto, identificada com o espaço, é, como ele, uma propriedade emergente. Toda a noção de matéria será coerente com 
a relativização do espaço e com a tese da criação primeira das substâncias. As substâncias são as últimas entidades reais de um todo que se assemelha a um grande organismo. A entidade real final é, em última análise, uma atividade organizadora alocada em infinitas unidades independentes e autônomas que são o constituinte do real. Esse sistema pressupõe um agregado de entidades independentes cujas perspectivas individuais, somadas, compõe o todo. As substâncias individuais, como reflexos individualizados da imagem divina representante do todo, funcionam como parte da ordem das coexistências fundadoras do espaço ideal, embora não haja entre elas qualquer relação espacial (Leibniz, 1989a, p. 667). Para Leibniz o espaço é algo como um sistema ideal de relação entre os corpos, enquanto para Clarke o espaço é o local ou receptáculo onde os corpos estão localizados e onde podem se mover.

O espaço só é pensado à medida que substâncias, individualmente passíveis de se tornarem existentes, e conjuntamente passíveis de dividirem um mesmo espaço, deixam de ser meras possibilidades. A idealidade do espaço se dá à medida que o ser pensado não é necessariamente o ser tornado real, mas apenas possível.

Surge uma dificuldade quando notamos a discutível definição da posição simples dos seres no espaço e no tempo. Esses seres, que foram afirmados como unidades independentes e fundamentos últimos da realidade, isto é, como entidades reais, são partes do processo de organização de um mundo que se apresenta de modo fenomênico. Trata-se do espaço estabelecido como situando uma relação de ordem lógica entre os compossíveis.

Não há outra definição de espaço para Leibniz na sua fase da maturidade: sua realidade é sua idealidade (Leibniz, 1989a, p. 669). Quando se trata dos seres compossíveis que foram tornados existentes a esfera espacial é a da realidade. Quando se está admitindo os seres apenas enquanto possíveis sua esfera é da idealidade. Os seres percebidos, existentes, estão situados no espaço real. Os seres possíveis, no espaço ideal. A necessidade de distinguir o espaço da extensão se deve a esta característica. É preciso haver mais do que a mudança no ponto 
de vista para que as relações fenomênicas se firmem. É preciso que haja a extensão, qualificando a aparência do real como o que se repete, assumida como um meio de tornar a diversidade (entendida como a multiplicidade lógica dos possíveis) presente no mundo fenomênico dos compossíveis. A extensão só tem sentido se pensada em relação aos fenômenos; não como parte da sua essência, mas caracterizando a resistência, o componente físico dos seres.

O espaço e o tempo, como a matemática, são quantidades contínuas e indeterminadas por si mesmas, indiferentes às partes que podemos tomar delas e que, na natureza, na matéria, são tomadas atualmente. A massa dos corpos está dividida atualmente de uma maneira determinada e nada nela é exatamente de modo contínuo, mas o espaço, ou a continuidade perfeita que há na sua ideia, não assinala mais do que uma possibilidade indeterminada de dividi-lo como se queira. Leibniz afirma, em uma carta para a princesa Sofia de 1705:

Na matéria e nas realidades atuais o todo é resultado das partes: mas nas ideias ou nos possíveis (que não compreendem apenas este universo, mas também qualquer outro que possa ser concebido e que no entendimento divino se apresente efetivamente), o todo indeterminado é anterior às divisões, como a noção de inteiro é mais simples que a da fração, e a precede. (LEIBNIZ, 1989, p.81).

Os corpos materiais são fenômenos que aparecem como contínuos mas que, uma vez fundados nas unidades substanciais, não passam de unidades discretas. As unidades substanciais, elas próprias, estão situadas num nível ontológico em que não há lugar para a continuidade: ainda que as diferenças entre duas substâncias seja infinitesimal, elas têm uma característica de independência. São quantidades discretas. Acima desse nível ontológico estão os fenômenos: sua continuidade, aparente, reveste as unidades nas quais estão fundados; há ainda um terceiro nível ontológico, o dos seres de razão.

"Toda substância criada é acompanhada de matéria", afirma Leibniz na sua Terceira Carta para Clarke. Entretanto, a matéria não pode produzir seus efeitos diretamente sobre a substância simples. Essa interferência direta, se possível, signi- 
ficaria uma alteração no universo lógico substancial causado pelo mundo físico. Isso significaria uma interferência da causalidade eficiente na causalidade final e, desse modo, o rompimento da ordem harmônica teleologicamente presente no universo, o que é impossível. Para que se mantenha a continuidade metafísica no universo é exigido que cada substância simples siga seu próprio caminho autônomo.

O que garante a ordem harmônica não é, fisicamente, a contigüidade dos corpos materiais; são os graus lógicos das substâncias individuais que, reunidas, embora sem interferirem umas nas outras, fundamentam os graus ontológicos da realidade do universo. Sem esse fundamento o universo não seria mais do que um agregado sem qualquer realidade em si mesmo. A questão que nos interessa ressaltar é que, para Leibniz, nem mesmo Deus pode interferir na autonomia ontológica das substâncias; muito menos o espaço. Não há nada que seja anterior às próprias substâncias, de modo que não se pode admitir um espaço absoluto em si, independente e de quem as substâncias dependeriam, como tampouco se pode admitir um espaço vazio em que não houvesse a atuação das substâncias.

Para Leibniz o espaço não é nada em si mesmo: ele é mera expressão de relações entre as coisas que existem. O espaço e o tempo se configuram como relações de compatibilidade ou incompatibilidade entre as coisas, sendo necessariamente posteriores a elas. O espaço é uma abstração a partir de distâncias entre os objetos físicos no tempo, é um conjunto de classes de equivalência de pares ordenados que consiste em objetos físicos e instantes de tempo. Sem objetos físicos e instantes de tempo não há lugares e, portanto, não há espaço.

\section{II}

O outro ponto da crítica leibniziana às concepções newtonianas envolve a ideia de que Deus eventualmente precisa 'dar corda' no mundo. Ela diz respeito à premissa de que o funcionamento da natureza, embora previsível, visto que ela é regida por leis deterministas, eventualmente apresenta va- 
riações que se mostram fundamentais para a manutenção da ordem estabelecida.

É bastante conhecida a posição newtoniana sobre a necessidade de um ajuste constante no mundo. Nas correspondências Clarke defende a necessidade dessa intervenção divina e afirma:

A ideia dos que sustentam que o mundo é uma grande máquina que se move sem a intervenção de Deus, como um relógio continua a andar sem o socorro do relojoeiro, essa ideia, digo, introduz o materialismo e a fatalidade, tendendo, de fato, sob pretexto de fazer de Deus uma Inteligência supramundana, a banir do mundo a providência e o governo de Deus. (CLARKE I, art. 4, p. 170).

Para Leibniz, entretanto, negar que Deus seja intelligentia supra mundana significará admitir que ele é Inteligência mundana, a Alma do mundo (Leibniz II, art. 10).

O que chama a atenção é que tanto Leibniz quanto Clarke estavam preocupados em garantir a presença de Deus como elemento necessário para a compreensão da existência do mundo organizado, mas discordavam em relação ao papel desempenhado pelo criador depois da criação. Ora, a reação dos newtonianos contra a crítica de Leibniz envolve um problema comum à época: com o estabelecimento crescente do mecanicismo é legítima a preocupação com a compreensão da matéria e do movimento e sua relação com Deus. Um teólogo como Clarke não poderia ficar indiferente ao risco de se assumir a validade das teses mecanicistas que, afinal, poderiam fazer de Deus um mero criador cuja existência seria totalmente desnecessária uma vez que ele tivesse concluído sua tarefa - criar.

Leibniz considera a tese da intervenção periódica de Deus na criação (manus emendatrix, Leibniz I, art. 3) equivalente a considerar a criação imperfeita, e Deus, um mau artífice.

A saída para esse problema passa pela transformação do papel de Deus como responsável não somente pela criação inicial da matéria e do movimento, mas, também, como responsável pela conservação do movimento nos corpos, ao modo do que se tem na filosofia cartesiana. Para Clarke e os newtonianos era imprescindível que houvessem tarefas a serem exe- 
cutadas por Deus para que não fosse possível o estabelecimento de um universo capaz de existir sem Ele. A proposta subjacente ao mecanicismo cartesiano permite afirmar que não é preciso recorrer a presença constante de Deus para explicar os desdobramentos dos eventos do mundo. A atuação absoluta das leis deterministas da natureza sobre os corpos seria suficiente para a explicação de tudo o que há. Descartes, ao dividir as substâncias e fazer incidir sobre as substâncias extensas, mas não sobre as substâncias pensantes, as leis da natureza, resolve a seu modo o problema que a visão mecanicista traz consigo ${ }^{5}$. Newton, diante de dificuldade parecida, afirma na Óptica que o mundo tende para a dissolução e que, por isso, precisa de reformas periódicas feitas por Deus:

For while Comets move in very excentrick Orbs in all manner of Positions, blind Fate could never make all the Planets move one and the same way in Orbs concentrick, some inconsiderable Irregularities excepted, which may have risen from the mutual Actions of Comets and Planets upon one another, and which will be apt to increase, till this System wants a Reformation. (Newton, 1952, p. 402)

David Kubrin em seu artigo Newton e o cosmo cíclico: a Divina Providência e a filosofia mecânica (1967) analisa a relação entre a Providência Divina e os elementos que estavam na base da filosofia mecanicista. Kubrin sugere que Newton se utilizou da ideia da reforma periódica do mundo por parte do Criador ainda quando não era capaz de explicar sua ocorrência. Ele se dedicou a investigar um possível mecanismo, controlado pela Providência Divina - visto que Deus precisa ter uma tarefa essencial a ser cumprida -, que permitisse sua execução. O modelo adequado foi encontrado quando da análise da periodicidade dos cometas. Era intrigante a diferença entre a previsibilidade e o ordenamento das órbitas dos planetas e a imprevisibilidade e o caráter aparentemente aleatório do movimento dos cometas. ${ }^{6}$

\footnotetext{
$5 \quad$ Cf. Descartes, 1996.

$6 \quad$ "To what end are Comets, and whence is it that Planets move all one and the same way in Orbs concentrick, while Comets move all manner of ways in Orbs very excentrick". (NEWTON, 1952, p.369, Q. 28).
} 
Para Leibniz a proposta newtoniana defendida por Clarke apresenta um mundo imperfeito que só poderia ser resultante de um criador imperfeito, a quem faltaria ou visão ou capacidade para construir uma máquina cósmica que pudesse durar sem sua interferência constante:

Uma verdadeira providência de Deus exige uma previsão perfeita, mas requer, além disso, que ele não somente tenha previsto tudo, mas também tenha provido a tudo por meio de convenientes remédios preordenados; caso contrário, ou the faltaria sabedoria para prevê-lo, ou poder para prover a isso. (LEIBNIZ II, art. 9).

Nos Princípios matemáticos de filosofia natural (1687) Newton apresenta sua concepção de espaço, lugar e tempo que, assim como o próprio movimento, são afirmados "conhecidíssimos de todos". O desenvolvimento da análise qualitativa e quantitativa das 'forças' que produzem o movimento, e que para Newton não são tomadas como relativas às formas substanciais, está presente na própria concepção dos Principia. Ali são investigadas também as relações e os tipos de forças que atuam sobre os corpos. Diz Newton:

ofereço este trabalho como os princípios matemáticos da filosofia, pois toda a essência da filosofia parece consistir nisso - a partir dos fenômenos do movimento, investigar as forças da natureza e, então, dessas forças demonstrar os outros fenômenos (NEWTON, 1990, p.14).

Ele pretende justificar as "questões metafísicas" (inércia, movimento, força) de um modo matemático, ou seja, pelos seus efeitos, pois desse modo escaparia de discutir a inteligibilidade metafísica das questões tratadas.

Podemos supor que parte das tentativas de Newton para defender que haveria uma causa para a gravidade - ainda que ele não pudesse dizer qual seria ela - foram elaboradas no sentido de evitar que sua teoria fosse incluída na categoria de recurso explicativo às qualidades ocultas. Na Questão 31 da Óptica Newton afirma, sobre os princípios ativos (gravidade, fermentação e coesão): 
These Principles I consider, not as occult Qualities, supposed to result from the specifick Forms of Things, but as general Laws of Nature, by which the Things themselves are form'd; their Truth appearing to us by Phenomena, though their Causes be not yet discover'd. For these are manifest Qualities, and their Causes only are occult. And the Aristotelians gave the Name of occult Qualities, not to manifest Qualities, but to such Qualities only as they supposed to lie hid in Bodies, and to be the unknown Causes of manifest Effects: Such as would be the Causes of Gravity, and of magnetick and electrick Attractions, and of Fermentations, if we should suppose that these Forces or Actions arose from Qualities unknown to us, and uncapable of being discovered and made manifest. Such occult Qualities put a stop to the Improvement of natural Philosophy, and therefore of late years have been rejected. (NEWTON, 1952, p. 401, q. 31).

Não é imediatamente claro, por exemplo, que a polêmica em torno do conceito de força gravitacional fosse uma questão relativa à inteligibilidade desse conceito. Newton e seus críticos concordavam com a idéia de que a gravidade se tornaria inteligível ou compreensível sob a condição de que alguma explicação fosse oferecida para sua ação (cf. KOYRÉ, 1968). O próprio Newton considerava absurda a idéia de ação à distância e, não obstante, julgava poder excluir tal caráter 'absurdo' fornecendo leis para a gravidade. Clarke enuncia claramente o caráter auto-contraditório dessa noção numa de suas cartas a Leibniz, cuja redação parece ter sido diretamente assessorada pelo próprio Newton (cf. COHEN, 1996, p.190): "É verdade que, se um corpo atraísse outro, sem a intervenção de qualquer meio, não teríamos um milagre, mas uma contradição, pois seria supor que uma coisa agisse onde não está" (Clarke IV, art. 45). Ainda assim Leibniz reprovava que a gravidade pudesse produzir seu "efeito sem empregar nenhum meio inteligível". "Mostrar a possibilidade" e "fornecer uma explicação" pareciam ser tomados como procedimentos metodológicos equivalentes para o caso da gravidade, muito embora esses autores soubessem distingui-los claramente em outros contextos.

A inteligibilidade das qualidades manifestas esteve associada à possibilidade de reduzi-las a algum dos quatros elementos da cosmologia sublunar aristotélica (cf. KOYRÉ, 1968). É possível que a situação não tenha se alterado muito com o advento da nova ciência. Antes de ser avaliada através da experi- 
ência a respeito de seu poder explanatório e preditivo, uma hipótese deveria mostrar-se possível, no sentido de ser inteligível.

Diante disso, em ao menos um sentido o conceito de força gravitacional seria inteligível: ele estava de acordo com os princípios dos movimentos locais estabelecidos nas seções iniciais dos Principia, em que se afirma que, para qualquer deslocamento dos corpos de seus estados inerciais, é necessária a ação de uma força. Mas, dessa forma, somente se adiaria a solução do problema, pois é justamente o conceito de "força", ou uma determinada interpretação dele, que está em questão.

\section{Considerações finais}

O espaço é descrito por Leibniz como uma relação entre objetos. Se fosse uma relação entre possíveis objetos, o espaço poderia ser concebido como absoluto, ao modo newtoniano, ou seja, independentemente da existência própria de qualquer objeto. Para evitar essa conclusão Leibniz afirma que uma posição não pode sequer ser percebida a não ser que haja um objeto. Assim, se não houver objeto, não haverá espaço. Para Leibniz o possível ocupa outro papel: o espaço pode ser concebido como uma possível relação que objetos coexistentes possam ter uns com os outros, afirmando, fundamentalmente, o espaço como a ordem dos objetos coexistentes. Daí o espaço leibnizano ser "relacional" já que se refere a colocação espacial de objetos em certa ordem, dado que só há relação de objetos entre si, afastando qualquer possibilidade de um espaço ao modo newtoniano.

Segundo Broad (1975), no que concerne à questão relacional do espaço quanto ao modo de distribuição dos corpos, o espaço seria visto como um constructo lógico sem lugares, e o lugar seria visto como um constructo lógico sem fatos: Leibniz assegurava que as noções de espaço e lugar absolutos não passavam de falácias.

Para ele, se o espaço pudesse ser dividido, seria necessário postular sua composição por partes, que, por sua vez, deveriam ser simples. Ora, o universo contínuo não aceita uma 
composição em partes $^{7}$. Se se realiza a divisão em unidades simples, em pontos, então desaparece o contínuo. Se se encontra o limite entre um e outro, então não é possível defender a continuidade entre eles. A solução de Leibniz parte da defesa de que é possível um espaço infinito com partes ("Dizer que o espaço infinito não tem partes equivale à afirmação de que os espaços finitos não o compõem"s) que, entretanto, são ideias quando tomadas em si mesmas. Ele continua, afirmando o espaço como tendo uma existência derivada, distinta da matéria:

Não digo que a matéria e o espaço são a mesma coisa: somente afirmo que não há espaço onde não existe matéria. (...) Essas coisas, entretanto, embora diferentes, são inseparáveis.

Ainda que sejam inseparáveis, "o espaço tomado sem as coisas nada tem de determinante, e, até, não é coisa alguma atual" 9. A idéia de espaço pertence ao âmbito dos conceitos que são aplicados à realidade sensível ou fenomênica ${ }^{10}$, enquanto noções como as de substância e força pertencem ao campo da verdadeira ontologia. Na ordem da criação, a substância é a primeira, o espaço é o derivado. Não podem ser concomitantes ou simultâneos.

Para Leibniz não há como tomar o espaço por real e absoluto por si mesmo pelo $\mathrm{PRS}^{11}$. Segundo esse princípio não há nenhuma razão para que Deus faça alguma distinção entre

$7 \quad$ A chamada 'lei da continuidade' que evita os saltos e os hiatos é assim apresentada por Leibniz: "Se duas condições hipotéticas ou dois dados diferentes se aproximam continuamente um do outro, então necessariamente os resultados mudam ou os efeitos das duas condições se aproximam também continuamente um do outro, finalmente se fundindo um no outro e reciprocamente" (Leibniz, Observações à parte geral dos Princípios de Descartes. GP, IV, §45).

8 Leibniz, IV, art.11. Na continuação do parágrafo o autor afirma: "Dizer que o espaço infinito poderia subsistir quando todos os espaços finitos fossem reduzidos a nada, seria como se se asseverasse (na suposição cartesiana de um universo corporal extenso sem limites) que esse universo poderia subsistir ainda que todos os corpos que o compõem fossem reduzidos a nada."

$9 \quad$ Leibniz V, art. 66-70.

10 Embora não seja o lugar de todas as coisas, porque não é o lugar de Deus. Leibniz V, art. 79.

11 Cf. Leibniz, G. W. Correspondência com Clarke. São Paulo: Abril cultural, 1979, Leibniz V, art.104. 
as regiões de um espaço homogêneo, vazio e infinito, tratando -as de maneiras diferentes, colocando matéria em algum ponto e deixando outros vazios. Qual o motivo da escolha do lugar destinado a receber a matéria? Segue-se que não há extensão uniforme ou espaço vazio.

Por outro lado, o espaço absoluto é um conceito fundamental para a consolidação da física newtoniana; ele existe como uma entidade em si mesma ${ }^{12}$. É no espaço absoluto que se dá o movimento; não de modo sensível, mas de um ponto de vista teórico. É o espaço absoluto quem dá consistência e sustentação lógica à mecânica newtoniana. Ao estabelecer as três leis do movimento (NEWTON, 1990, p. 53-54) Newton define uma estrutura conceitual em que o espaço absoluto, não-sensível, homogêneo, infinito, é imprescindível e serve como referência para a determinação da posição e dos movimentos dos corpos. Antes disso, há uma famosa experiência newtoniana (o experimento do balde) em que se assume a prova do espaço absoluto (NEWTON, 1990, p. 49-50) ${ }^{13}$. As leis do movimento estabelecem a diferença entre o chamado movimento natural (ou sem causa) e o movimento resultante da ação de forças. Pelo chamado princípio de inércia se afirma que todo corpo em movimento ou repouso continua no seu estado desde que não haja a ação de outro corpo sobre ele. Compreendemos melhor essa tese quando consideramos que a determinação do movimento ou repouso de um corpo, calculada sempre em relação a outros corpos, precisa da postulação do espaço absoluto como referencial para a análise do movimento ou repouso dos corpos independentemente uns dos outros. É a postulação de um espaço absoluto o que garante a coerência da primeira lei ao afirmar algo sobre o movimento retilíneo ou o repouso de um determinado corpo. Ao mesmo tempo, em relação à segunda lei, ele possibilita a definição dos movimentos acelerados como sendo aqueles sujeitos a ação de forças. Assim, a proposta de um

$\overline{12}$ Daqui se tira a conexão entre o espaço absoluto e espaço vazio, encontrada nas Correspondências, mas que não será abordada aqui: o espaço absoluto newtoniano é na ausência completa de corpos, já que não depende ontologicamente da matéria, ou seja, é admitida a possibilidade de um espaço vazio.

13 Sobre o experimento do balde cf. Assis, 1997, p. 49-61. 
espaço absoluto define uma classe de objetos em relação aos quais as leis do movimento podem ser aplicadas, o que aponta a importância desse conceito na filosofia newtoniana. Segundo Barra (2000) o espaço newtoniano é uma região estacionária em que os objetos existem e se movem, mas da qual são totalmente independentes. Leibniz recusa a solução newtoniana para a questão do movimento e suas conseqüências, inclusive a que define a natureza dos objetos em relação ao espaço.

\section{Referências}

Assis, A. K. T. A experiência do balde de Newton. In: A. F. Siqueira e J. B. Bastos Filho (eds.). Reflexões sobre os Fundamentos da Física Moderna. Maceió: Edufa1, 1997, p. 49-61.

Barra, E. S. O. De Newton a Kant: a metafísica e o método da ciência da natureza. São Paulo, Faculdade de filosofia, letras e ciências humanas, 2000. Tese de doutorado.

Broad, C. D. Leibniz. Ed. C. Lewy. Cambridge university press, 1975.

Cohen, B. Westfall, R. S. Newton Texts Backgrounds Commentaries. Norton Critical Editions, 1996.

Descartes, R. Les principles de la philosophie. Paris: Vrin, 1996. (Oeuvres de Descartes, publiées par Ch. Adam et P. Tannery, tome IX).

Koyré, A. Études Newtoniennes. Paris: Gallimard, 1968.

Kubrin, D. Newton and the Cyclical Cosmos: Providence and the Mechanical Philosophy. In: Journal of the History of Ideas, Vol. 28, $\mathrm{N}^{\circ}$ 3 (Jul-Sep, 1967), p.325-346.

Leibniz, G. W. (1875-1890). Die philosophischen Schriften von G. W. Leibniz. Ed.C. J. Gerhardt, Berlin, reedição G. Olms, Hildesheim, 1965, vol. II, IV (GP)

Leibniz, G. W. (1715-6). Correspondência com Clarke. Trad. C. L. Mattos. São Paulo: Abril Cultural, 1979. Vol. I.

Leibniz, G. W. Escritos filosóficos. Ed. E. de Olaso. Madrid, A. Machado, 1982.

Leibniz, G. W. Filosofia para princesas. Ed. J. Echeverría. Madrid: Alianza Editorial, 1989.

Leibniz, G. W. (1714-1716). The Metaphysical Foundations of Mathematics. In: Philosophical papers and letters. Ed. L. Loemker. Kluwer Academic Publishers, 1989a, p. 666-674. 
Lodge, P. The Leibniz - De Volder correspondence. New Haven and London: Yale University Press, 2007.

Newton, I. (1704). Opticks. New York: Dover publications, 1952.

Newton, I. (1687) Principia: Princípios matemáticos de filosofia natural. Trad. T. Ricci...[et al]. São Paulo: Edusp, 1990. 